\title{
Perancangan Infografis Tentang School Bullying Menggunakan Teknik Motion Graphic
}

\author{
Mayriensa Widya Pangestieka ${ }^{1}$, Elfa Olivia Verdiana ${ }^{2}$ \\ ${ }^{1,2,3}$ Desain Komunikasi Visual, ${ }^{4}$ Informatika \\ ${ }^{1}$ mayriensa@yahoo.co.id, ${ }^{2}$ elfairy31@icloud.com
}

\begin{abstract}
ABSTRAK
Sekolah merupakan jenjang pendidikan yang harus dilalui sebelum meneruskan ke tingkat yang lebih tinggi. Di lingkungan sekolah bullying terus terjadi, bahkan cenderung diwariskan dan hadir dalam berbagai bentuk yang tidak kita sadari. Kasus kekerasan di sekolah menengah atas merupakan yang paling tinggi. Sehingga diperlukan untuk merancang sebuah media infografis yang dapat menyampaikan pesan tentang school bullying di tingkat SMA menggunakan teknik motion graphic. Untuk membuat sebuah media infografis dibutuhkan pengumpulan data melalui metode studi pustaka dan wawancara. Kemudian data yang diperoleh dirangkum dan dianalisa menjadi poin-poin penting. Tahapan perancangan infografis berupa visualisasi pembuatan objek karakter dan background, proses editing penambahan effect dan audio hingga yang terakhir adalah tahapan rendering. Elemen visual dan audio dikomposisikan menggunakan teknik motion graphic yang membuat target audience lebih cepat dan mudah untuk memahami informasi yang ada dalam infografis. Kesimpulan dari perancangan infografis ini yaitu pentingnya keahlian dalam desain grafis, keterampilan dalam menerapkan effect dan memperbanyak referensi tentang infografis. Distribusi infografis ini diupload di channel youtube kemudian link akan dishare di grup-grup SMA. Selain itu akan digunakan sebagai media pembelajaran oleh guru bimbingan konseling. Berdasarkan hasil pengujian produk melalui kuesioner dapat diambil kesimpulan bahwa responden menanggapi infografis ini dengan baik dan sangat layak untuk dipublikasikan.
\end{abstract}

Kata Kunci: Infografis, Motion Graphic, School Bullying.

\section{ABSTRACT}

School is the level of education that must be passed before continuing to a higher level. In a school environment bullying continues to occur, even it tends to be inherited and present in various forms that we do not realize. The case of violence in high school is the highest. So it is necessary to design an infographic media that can convey messages about school bullying at high school level using motion graphic technique. To make an infographic media it is necessary to collect data through interview method and literature study. Then the datum obtained are

summarized and analyzed into important points. Stages of infographic design in the form of visualization of making object characters and background, the process of editing the addition of effects and audio until the last stage is rendering. Visual and audio elements are composed using motion graphics techniques that make the target audience understand the information contained in the infographics faster and easier. The conclusion of this infographic design that is the importance of expertise in graphic design, skills in applying effects and reproduce references about infographics. This infographic distribution is uploaded on youtube channel then the link will be shared in high school groups. In addition it will be used as a medium of learning by counseling teachers. Based on the results of product testing through questionnaires, it can be concluded that respondents responded to this infographis well and very worthy to be published.

Keywords: Infographic, Motion Graphic, School Bullying.

\section{PENDAHULUAN}

Kasus school bullying menduduki peringkat teratas pengaduan masyarakat ke Komisi Perlindungan Anak Indonesia (KPAI) di sektor pendidikan. Dari 2011 sampai Agustus 2014, KPAI mencatat 369 pengaduan terkait masalah tersebut. Jumlah itu sekitar $25 \%$ dari total pengaduan di bidang pendidikan sebanyak 1.480 kasus. Bullying yang disebut 
KPAI sebagai bentuk kekerasan di sekolah mengalahkan kasus tawuran pelajar, diskriminasi pendidikan, ataupun aduan pungutan liar (Halimah, 2015:130).

Penelitian yang dilakukan oleh Yayasan Semai Jiwa Amini tentang kekerasan bullying di kota besar di Indonesia, yaitu Yogyakarta, Surabaya, dan Jakarta mencatat terjadinya tingkat kekerasan sebesar 67,9\% terjadi di tingkat Sekolah Menengah Atas (SMA) (Wiyani, 2012:18). Bentuk school bullying yang terjadi pada siswa SMA dapat berupa mengejek, menyebarkan rumor, menghasut, mengucilkan menakut-nakuti, intimidasi, mengancam, menindas, memalak, menyerang secara fisik, mendorong, menampar, atau memukul.

Pada usia SMA anak disiapkan untuk memilih melanjutkan pendidikan atau pilihan hidup selanjutnya. School bullying yang terjadi di tingkat SMA akan berdampak bagi kehidupan anak di sekolah maupun di dalam masyarakat. Tindakan school bullying dapat memberikan dampak kecemasan perlakuan tidak menyenangkan dari teman-teman dan depresi karena mengalami penindasan, menurunnya minat untuk mengerjakan tugas-tugas sekolah yang diberikan oleh guru, dan menurunnya minat untuk mengikuti kegiatan sekolah. Selain itu korban akan mengalami kesulitan dalam menjalin hubungan baik terhadap orang sekitar. Dampak yang paling parah adalah keinginan untuk bunuh diri.

Teknologi informasi mengalami perkembangan yang pesat, untuk menyampaikan informasi tentang school bullying dapat melalui media infografis. Media ini dapat menyampaikan pesan secara singkat dan jelas dengan gambar atau ilustrasi. Gambar atau ilustrasi merupakan bahasa yang dapat menyatukan semua bahasa di seluruh dunia. Indonesia memiliki berbagai macam bahasa, sehingga penggunaan infografis ini sangat membantu siswa SMA memahami informasi hanya dengan menontonnya.

Teknik motion graphic membuat gambar atau ilustrasi pada infografis dimanipulasikan seolah-olah bergerak. Dilengkapi dengan pesan suara akan membuat penonton mengetahui informasi yang disampaikan. Selain itu dengan lebih banyak efek animasi dan sound yang sesuai dengan tampilan effect, infografis ini akan menarik dibandingkan dengan media konvensional seperti buku atau media lainnya. Sehingga dengan menggunakan teknik motion graphic dapat membantu mempertajam pesan yang disampaikan dengan kelebihan menarik indera dan minat, karena merupakan gabungan antara padangan, suara dan gerak.

Oleh karena latar belakang tersebut penelitian ini berjudul "Perancangan Infografis Tentang School Bullying Menggunakan Teknik Motion Graphic". Infographic atau dalam bahasa indonesianya "Infografis" yang merupakan kependekan untuk "grafis informasi". Istilah ini belakangan telah meraih popularitas berdasarkan peningkatan penggunaan grafis dalam pemasaran online selama beberapa tahun terakhir. Sebagian orang menggunakan istilah ini untuk mengartikan format unik yang telah digunakan secara luas untuk aplikasi ini, yang dicirikan dengan ilustrasi, tipografi besar dan orientasi memanjang, vertikal yang menampilkan berbagai fakta (Crooks, 2002:20).

Adapun deskripsi produk adalah berikut ini:

Tabel 1 Deskripsi Produk

\begin{tabular}{ll}
\hline Jenis Produk & Info grafis dalam bentuk video dua dimensi \\
\hline Tema & School Bullying \\
\hline Judul Produk & INFOGRAFIS TENTANG SCHOOL \\
& BULLYING \\
\hline Target Produksi & $\begin{array}{l}\text { Pelajar Sekolah Menengah Atas berusia 15-19 } \\
\text { tahun }\end{array}$ \\
\hline Media Distribusi & Media online dan media offline \\
\hline
\end{tabular}


Infografis ini menggunakan layout yang tidak standart dan elemen elemen yang ditampilkan tidak teratur namun desain yang dihasilkan tetap efektif. Jenis layout yang digunakan adalah layout circus. Untuk beberapa scene seperti pada scene fakta-fakta bullying dan dampak bullying menggunakan layout mondrian yang tata letak elemennya mengacu pada bentuk kotak yang konseptual. Setiap elemen sejajar dan informasi yang disampaikan terstruktur. Hal ini bertujuan untuk memudahkan target audience dalam menangkap pesan. Dalam infografis ini memiliki storyboard yang dapat dilihat pada Tabel 3.5 :

Tabel 2 Storyboard

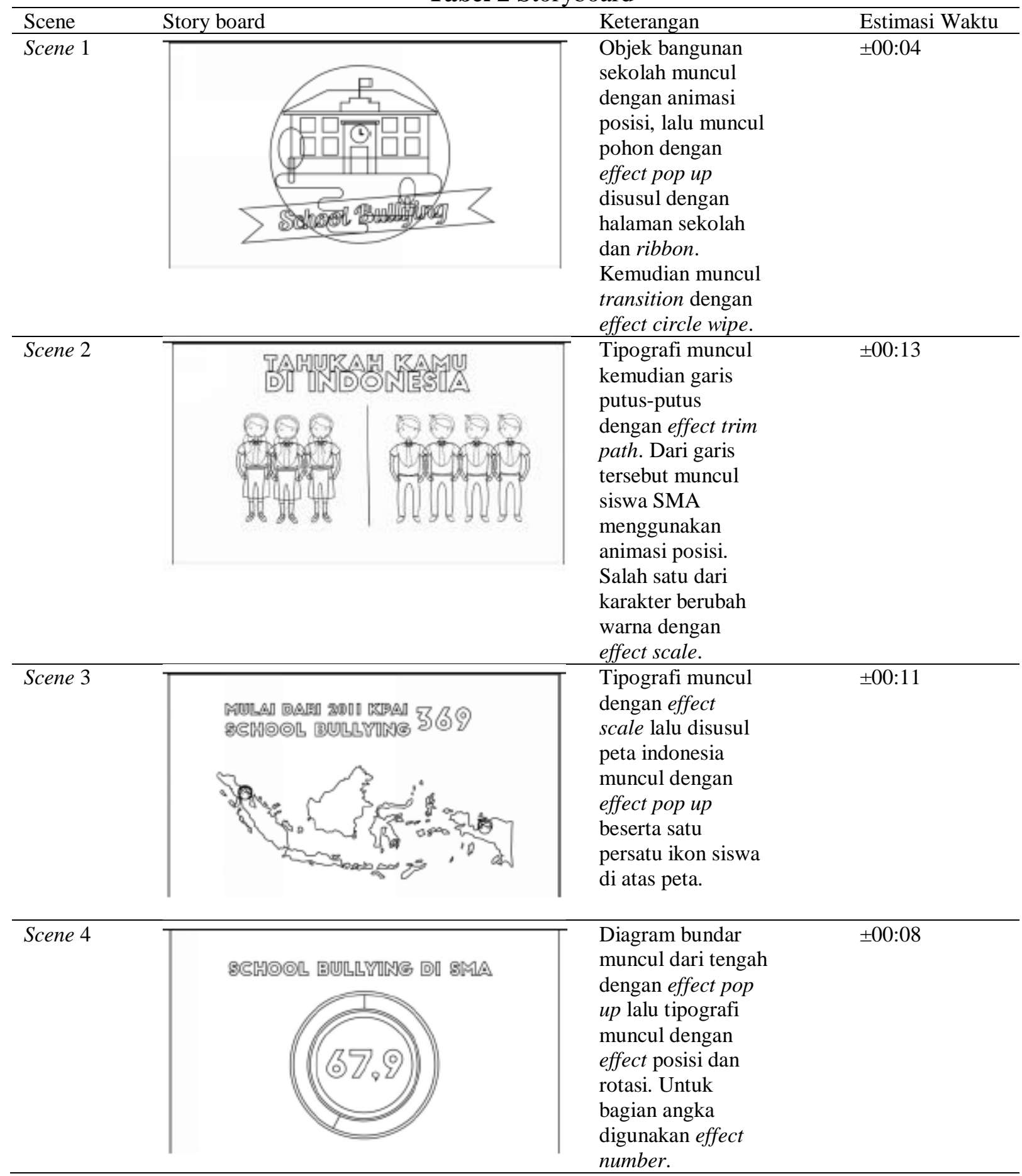




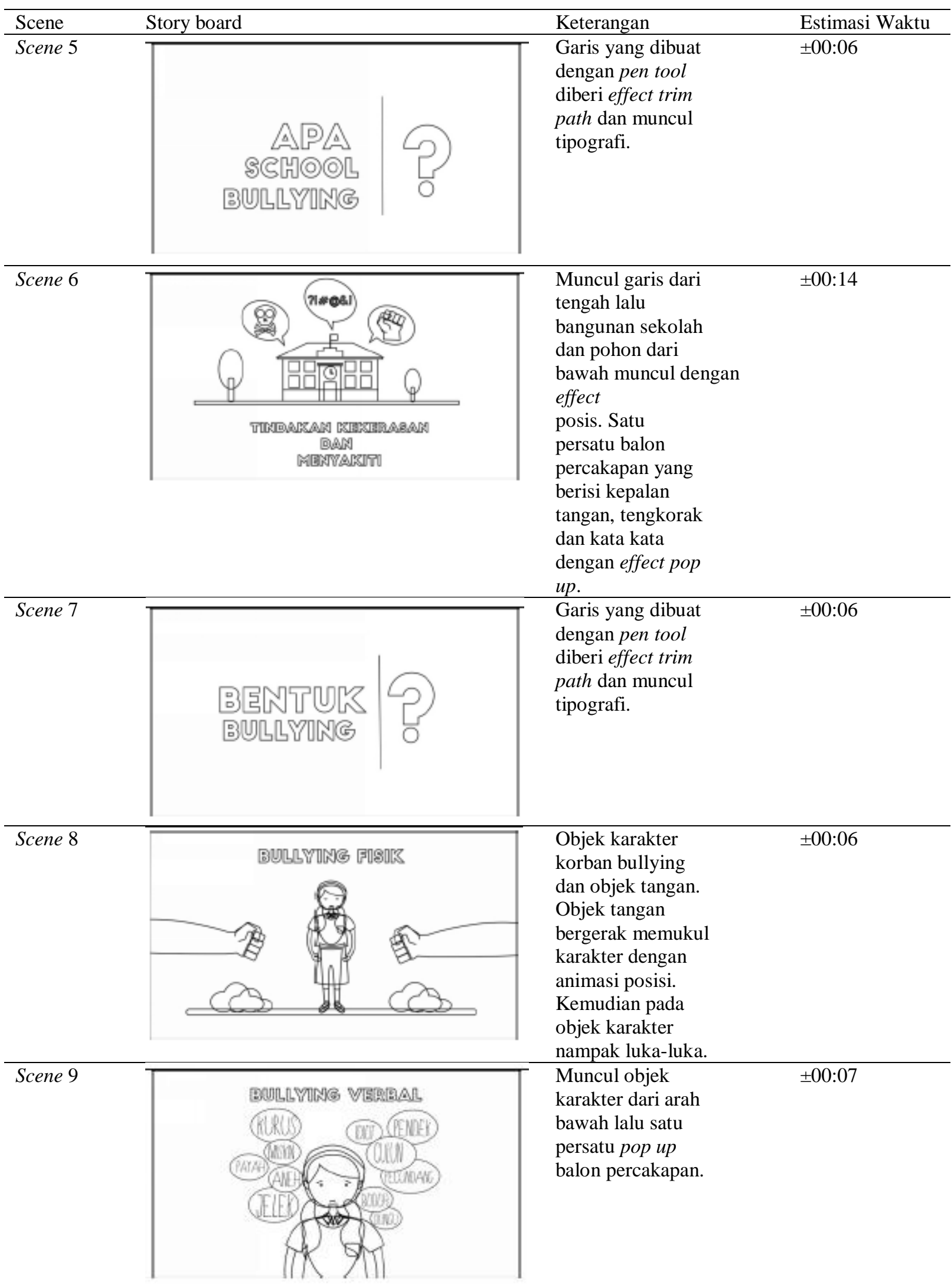




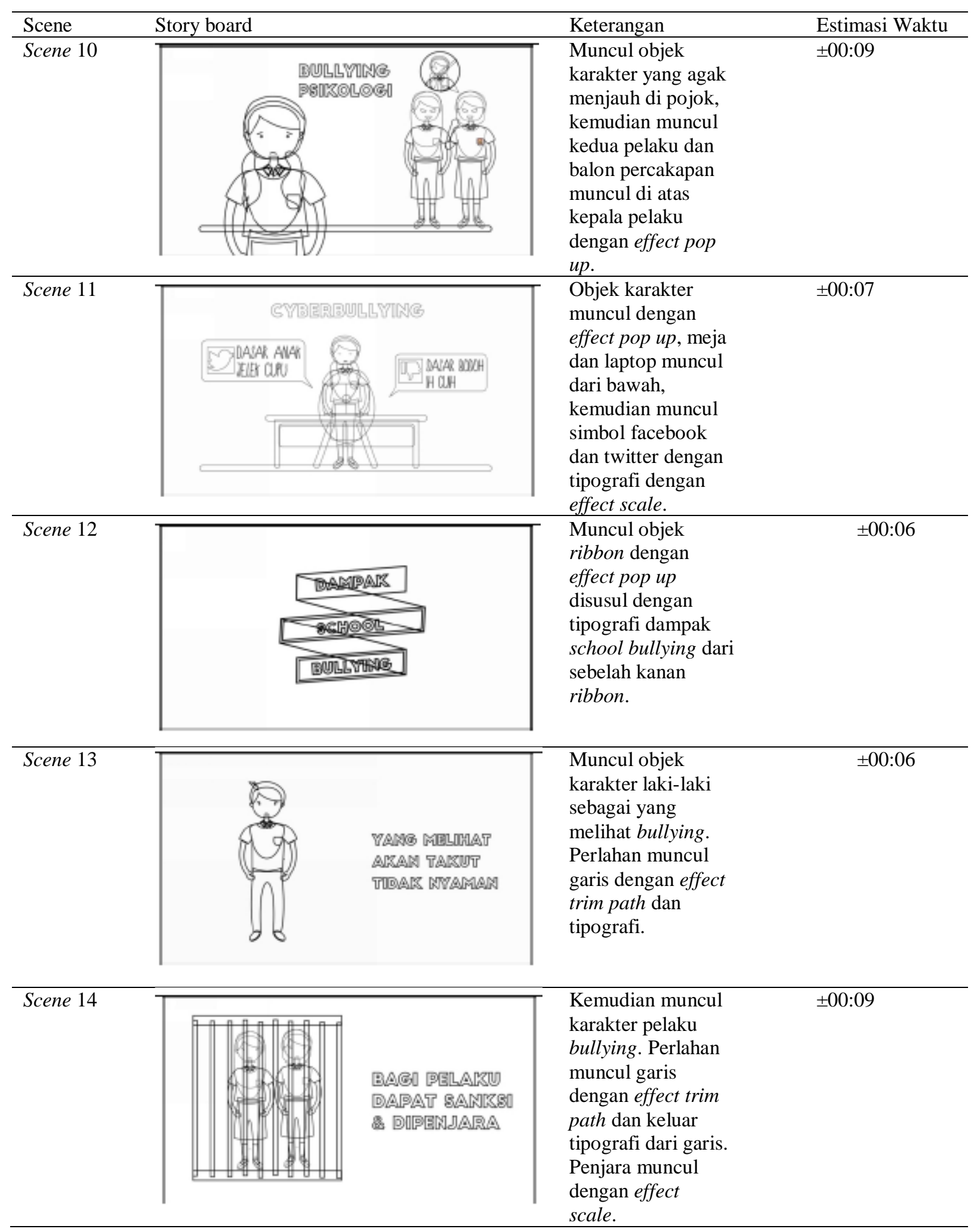




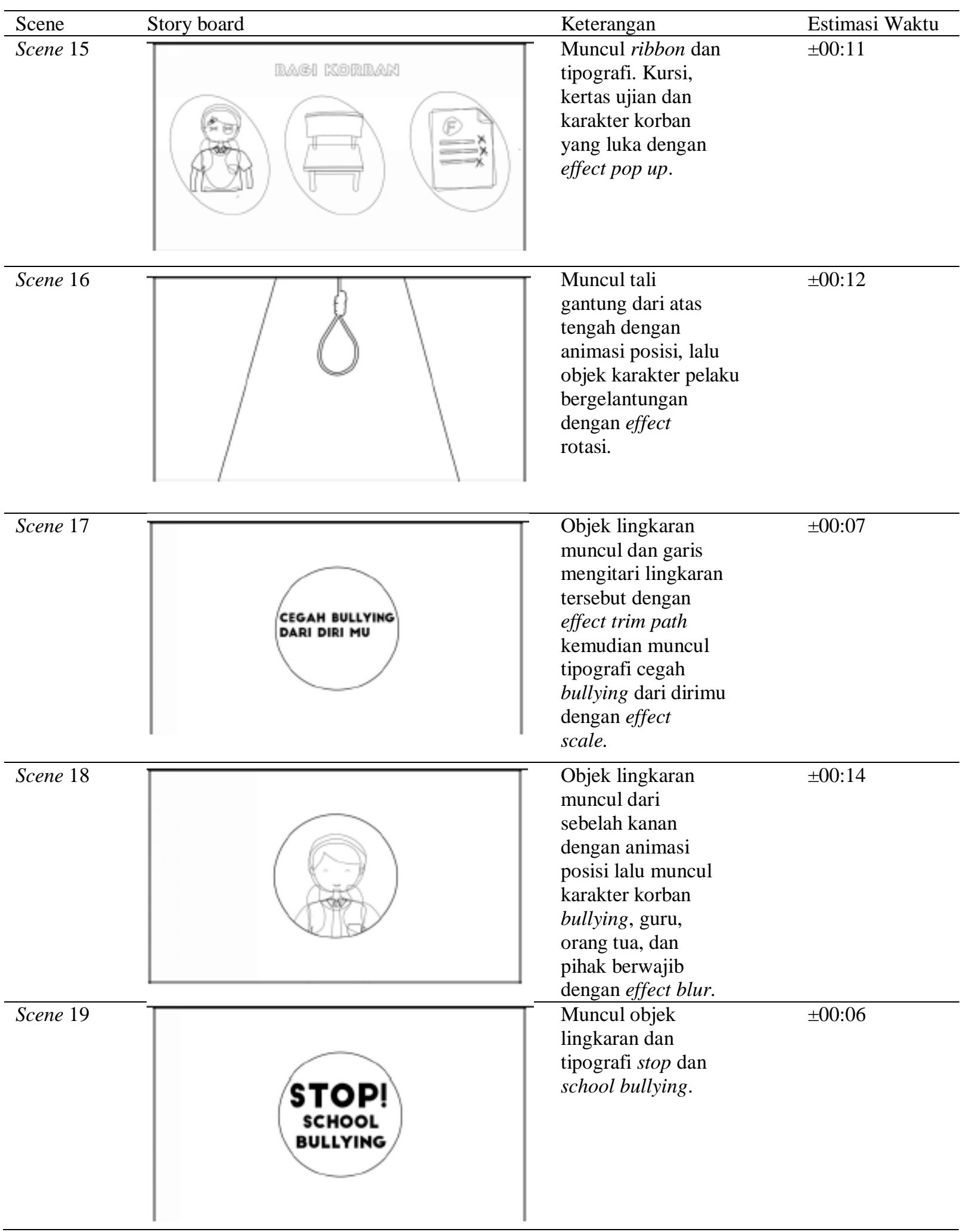

\section{PEMBAHASAN}

\section{Produksi}

Pada pembuatan infografis tentang school bullying ini ada beberapa tahapan yang terdiri dari visualisasi berupa proses pembuatan objek dan background. Tahapan selanjutnya 
penganimasian dan penambahan sound effect. Kemudian tahap terakhir adalah tahap rendering.

Tahapan pertama yaitu membuat new file pada adobe illustrator CC 2015. Kemudian masuk ke dalam artboard berukuran 1280 x 720 pixel. Buat sebuah layer yang digunakan sebagai background berwarna putih dan kunci layernya (control-2) agar layer tidak tergesergeser posisinya. Kemudian dilakukan proses menggambar dengan menggunakan pen tool (P) untuk membuat garis garis pada objek karakter.

Dimulai dari bagian badan yang besar dan secara perlahan pindah ke bagian yang kecil. Setiap membuat komponen badan, kaki, atau kepala usahakan selalu dipisah per layer agar memudahkan dalam mengedit dan penganimasian nanti. Harus dipastikan fill kosong dan stroke berwarna hitam. Semakin sedikit anchor points yang dibuat maka akan semakin halus garis yang akan dibentuk. Proses menggambar objek karakter dapat dilihat pada Gambar 3.

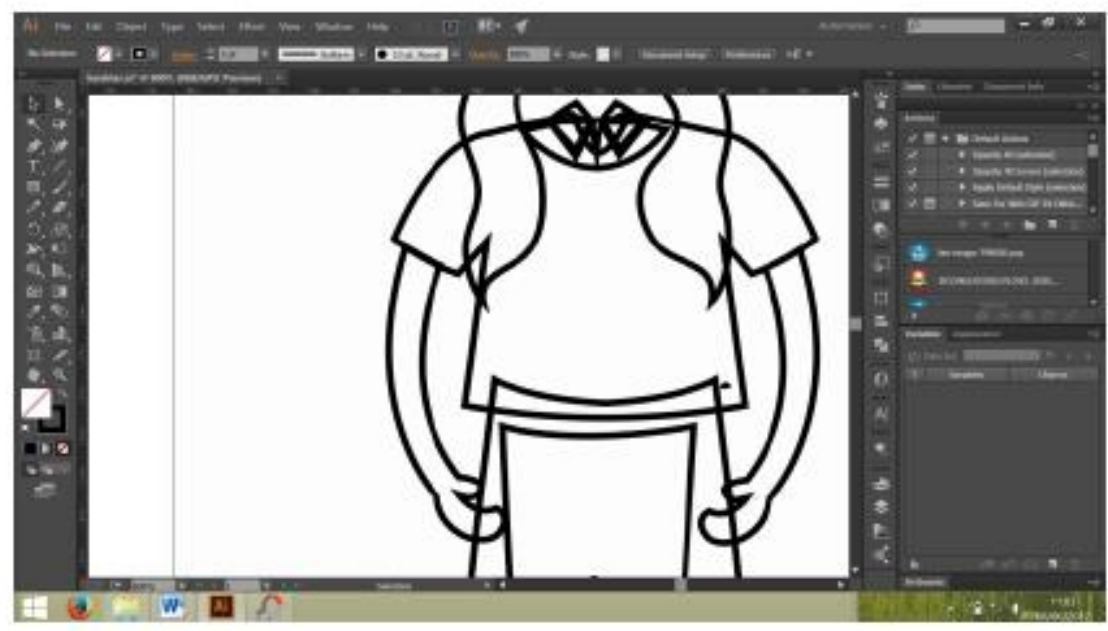

Gambar 1. Proses Menggambar

Setelah kerangka objek karakter terbentuk dilanjutkan dengan proses pewarnaan. Klik komponen objek yang ingin diwarnai dan buka panel swatches (window > swatches). Lalu pilih warna yang diinginkan. Proses pewarnaan dapat dilihat pada Gambar 2.

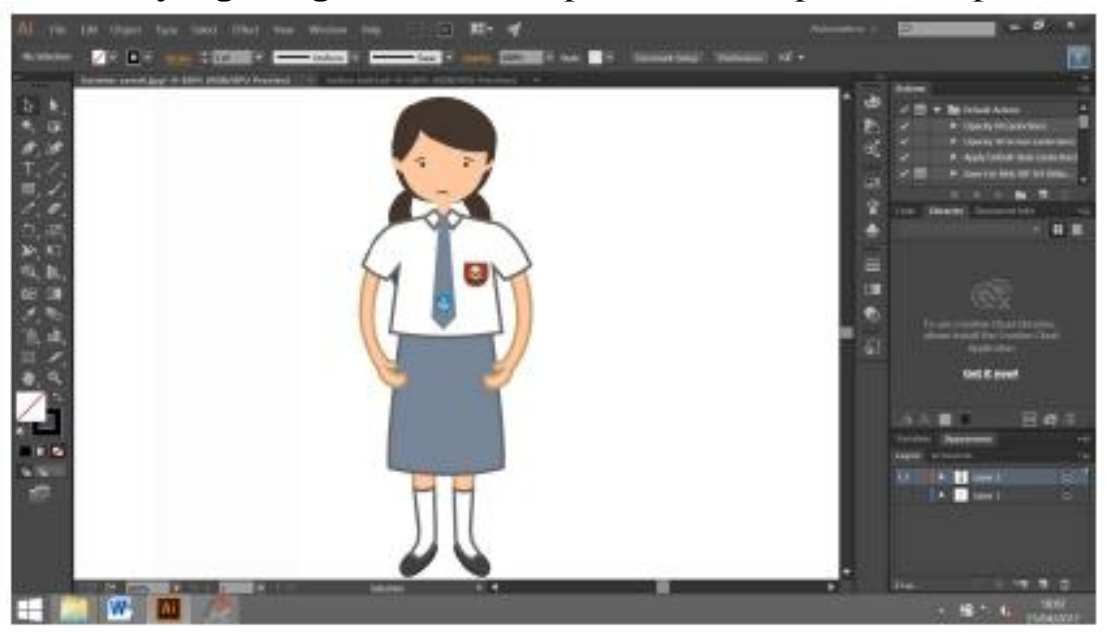

Gambar 2. Proses Pewarnaan 
Proses visualisasi objek meja, laptop, balon percakapan dan background juga sama dengan visualisasi objek karakter yaitu dengan masuk ke new file, lalu proses menggambar menggunakan pen tool, dan terakhir proses pewarnaan. Sama dengan objek karakter setiap komponen objek lainnya juga dipisahkan dengan layer baru agar mudah diedit kembali. Gambar proses pembuatan kerangka objek dan background bisa dilihat pada Gambar 3.

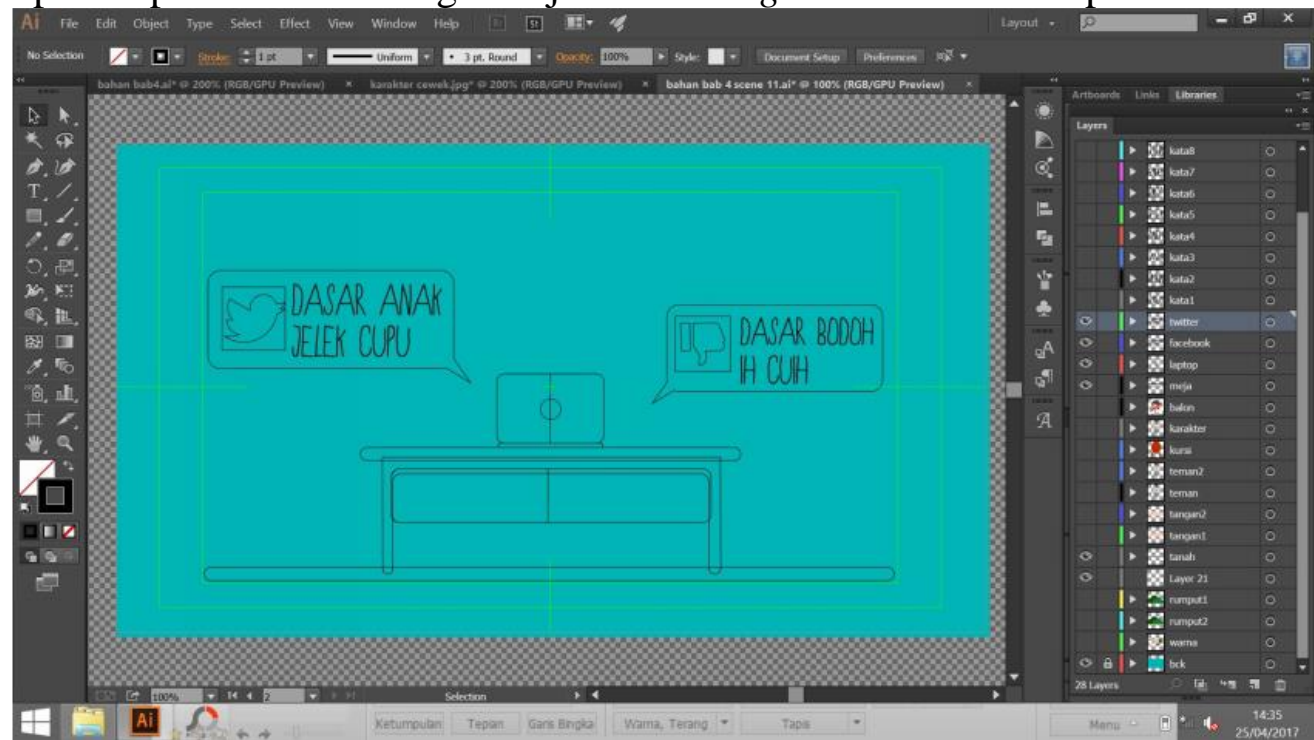

Gambar 3. Kerangka Objek dan Background

Hasil kerangka objek dan background yang selesai di warnai dapat dilihat pada Gambar 4 .

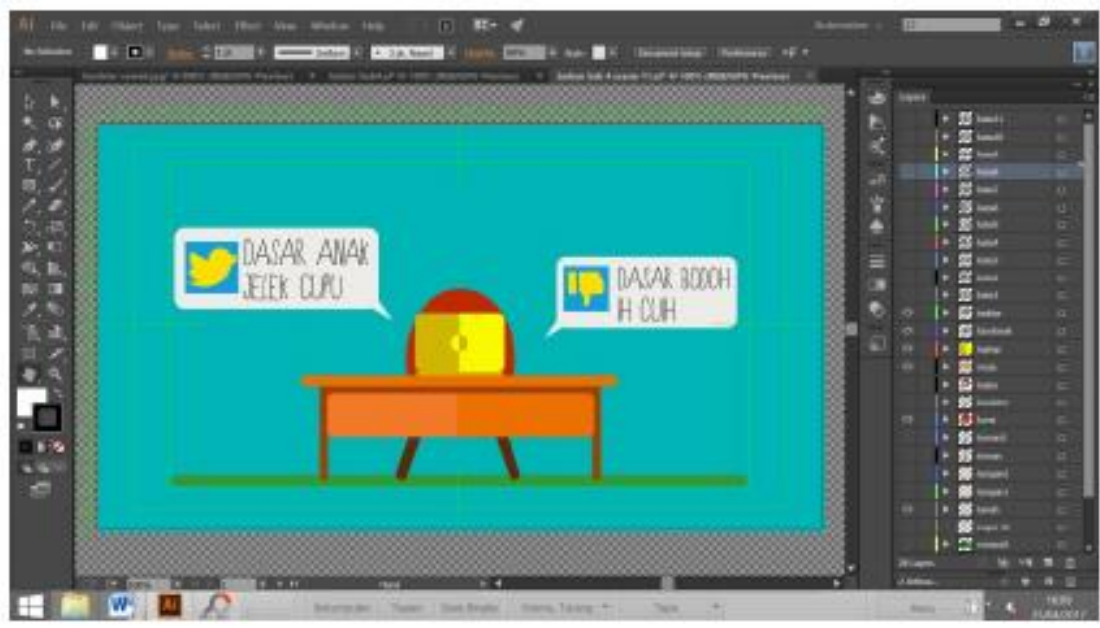

Gambar 4. Hasil yang Telah Diwarnai

Setelah proses menggambar dan pewarnaan selesai komponen masing-masing objek di tata sedemikian rupa sesuai dengan rancangan. Untuk komponen objek yang akan dianimasikan di letakkan pada layer yang berbeda. Kemudian file disimpan dengan format Adobe Illustrator yaitu *ai agar bisa dimasukkan ke dalam adobe after effect dan dapat dianimasikan. Cara menyimpannya yaitu dengan klik menu file $>$ save atau dengan shortcut ctrl + S. File diberi nama sesuai dengan urutan masing-masing scene kemudian klik save. Cara menyimpan hasil visualisasi dapat dilihat pada Gambar 5. 


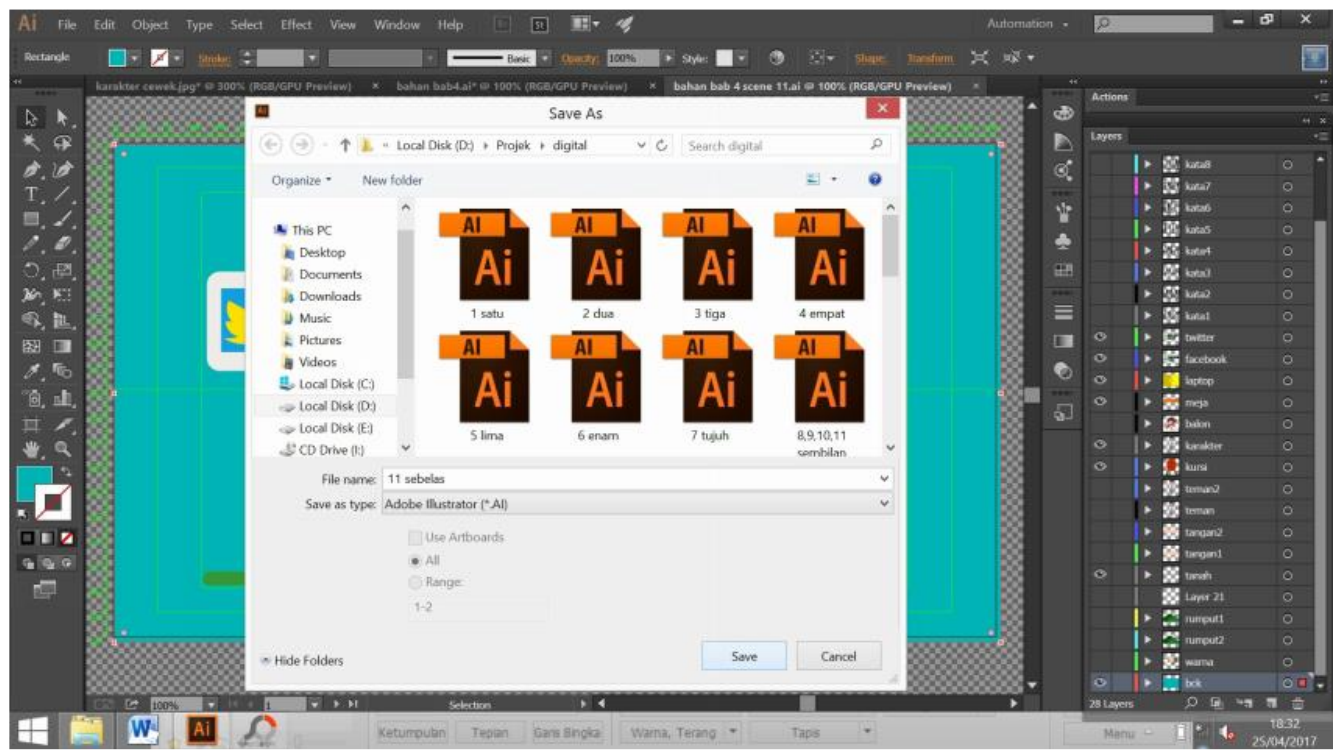

Gambar 5. Menyimpan Hasil Visualisasi

Tahapan kedua adalah proses editing. Menganimasikan adalah langkah selanjutnya setelah proses visualisasi. Dalam proses ini dilakukan beberapa langkah dengan menggunakan software Adobe After Effect. Langkah-langkah tersebut adalah New Composition > Import File(Vector) > Komposisi Animasi Grafik Visual > Tambah Effect $>$ Pengaturan Timeline > Komposisi Sound effect $>$ Preview Hasil Animasi > Render per scene.

Tahapan ketiga adalah rendering akhir. Pada tahap ini dilakukan proses penggabungan video per scene menggunakan software adobe premiere CC 2015. Langkah pertama adalah membuat projek baru dengan cara klik file > new > project. Kemudian mengimport semua file video, klik kanan pada window project $>$ import $>$ pilih file $>$ open.

Hasil akhir infografis school bullying ini menggunakan format video .mp4, pada bagian export setting diubah menjadi H.264. Format mp4 ringan dibandingkan dengan format avi. Format ini akan tetap menggunakan ukuran layar asli video yaitu $1280 \times 720$ pixel. Kemudian klik output name akan mengubah nama file video dan tempat penyimpanan hasil render. Beri tanda check list pada export video dan export audio agar semua file lengkap di render. Terakhir klik tombol export maka akan dilakukan proses rendering. Hasil rendering berupa file video dengan format mp4. Hal ini dapat dilihat pada Gambar 6.

\section{Pasca Produksi}

Distribusi infografis tentang school bullying ini dilakukan secara langsung (online) dan tidak langsung (offline). Untuk media distribusi online digunakan youtube, sedangkan untuk media tidak langsung infografis akan di distribusikan ke SMA Widyagama dan MA Daarul Ukhuwwah Malang tempat diadakannya kuesioner.

a. Infografis ini di upload di channel youtube. Kemudian dilakukan share link video ke media sosial facebook. Share Link diposting di grup-grup facebook dengan anggota berusia 15-19 tahun dan bersekolah di tingkat sekolah menengah atas dan sederajat.

b. Untuk media offline sesuai dengan target audiens yaitu remaja usia 15-19 tahun di tingkat sekolah menengah atas dan sederajat. Infografis ini didistribusikan ke SMA Widyagama dan MA Daarul Ukhuwwah Malang dan akan digunakan sebagai media pembelajaran di Bimbingan Konseling. Infografis didistribusikan dalam CD 
(Compact Disc) dan dikemas menarik sehingga dapat digunakan dengan mudah dan praktis.

\section{Pengujian Produk}

Pengujian produk infografis school bullying ini dilakukan dengan cara penyebaran dalam bentuk kuesioner kepada 40 responden untuk diminta mengisi lembar kuesioner dengan 9 pertanyaan. Kuesioner ini dibagikan kepada murid sekolah menengah atas dan sederajat berumur 15-19 tahun berjenis kelamin perempuan dan laki-laki. Kelayakan infografis school bullying ini tergantung pada hasil kesimpulan yang didasarkan pada pengisian kuesioner yang dilakukan oleh 40 responden tersebut.

Pengujian yang terdapat pada lembar kuesioner akan dianalisa dengan cara menghitung presentasi setiap jawaban responden menggunakan skala guttman. Skala pengukuran dengan jenis ini hanya ada dua interval dan akan mendapatkan jawaban yang tegas berupa "ya" atau "tidak". Untuk jawaban hasil responden akan dibagi dengan jumlah responden kemudian di kali seratus. Berikut ini rumus yang digunakan untuk menganalisis kuesioner :

$$
\text { Presentasi jawaban }(\mathrm{Ay})=\frac{\text { Jawaban responden }}{\text { Jumlah responden }} \times 100 \%
$$

Kemudian hasil kuesioner tersebut dikonversikan ke dalam bentuk kategori kelayakan. Hal ini dapat dilihat pada Tabel 3.

Tabel 3. Kategori kelayakan

\begin{tabular}{cc}
\hline Presentasi nilai $($ Ay) & Kategori \\
\hline $80 \%<\mathrm{Ay} \leq 100 \%$ & Sangat Layak \\
\hline $60 \%<\mathrm{Ay} \leq 100 \%$ & Layak \\
\hline $40 \%<\mathrm{Ay} \leq 100 \%$ & Cukup Layak \\
\hline $20 \%<\mathrm{Ay} \leq 100 \%$ & Kurang Layak \\
\hline $0 \%<\mathrm{Ay} \leq 100 \%$ & Tidak Layak \\
\hline
\end{tabular}

Untuk sistem penilaian menggunakan skala pengukuran dengan tipe hanya ada dua interval, yaitu "Ya-Tidak". Jawaban hasil responden apabila jawab "Ya" menggunakan skor A dan jawaban "Tidak" menggunakan skor B pada NH (Nilai Hasil).

Dari seluruh data yang diperoleh maka penilaian terakhir adalah jumlah nilai dari presentase jawaban dibagi jumlah soal untuk mendapatkan niai akhir. Nilai akhir inilah yang menjadi tolak ukur keberhasilan infografis ini. Berikut adalah definisi rumus yang digunakan

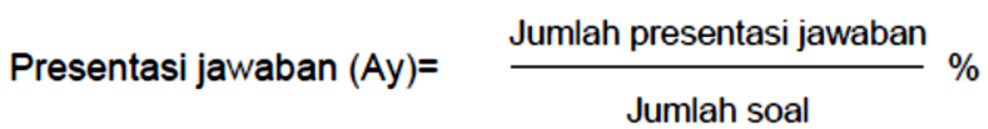

Setiap pertanyaan memiliki presentase dan memiliki rata-rata, untuk setiap pertanyaan total jawaban "Tidak" 20\% dan Total jawaban "Ya" $80 \%$, di ambil kesimpulan bahwa hasil presentase tersebut responden menanggapi sangat bagus dengan nilai $80 \%$ tentang produk ini. Sekian banyak responden maka diambil kesimpulan dari hasil testimoni para responden yang di ambil dari laki-laki perempuan remaja, berumur 15-19 tahun. Para 
responden menanggapi dengan baik, karena infografis ini menggandung informasi dan penyampaian dengan animasi motion graphic yang jelas dan tidak jenuh jika dilihat dalam memahami informasi tentang school bullying.

\section{KESIMPULAN}

Kasus school bullying meningkat setiap tahunnya terutama di tingkat sekolah menengah atas. Orang menganggap bahwa school bullying adalah suatu tindakan yang sepele dan normal dalam tahap kehidupan anak di sekolah. Infografis tentang school bullying ini ditujukan kepada siswa di tingkat SMA dan sederajat. Perancangan infografis ini dibuat dengan menganalisa data-data yang sudah ada lalu dibuat sebuah informasi yang singkat dan jelas. Informasi yang disampaikan berupa pengertian, bentuk-bentuk dan dampak dari school bullying.

Konsep yang diambil yaitu penyajian informasi berupa gambar, tipografi dan audio dengan menggunakan karakter pelajar SMA sebagai korban, pelaku dan yang melihat school bullying. Pada saat proses perancangan mengalami beberapa kali perubahan warna. Warna yang digunakan mendekati realis karena target audience yang berusia remaja akhir akan lebih mudah menangkap pesan dengan warna yang realis.

Jenis tipografi yang dipakai bersifat nonformal dan mudah dibaca. Perbedaan warna pada tipografi memberi kesan tegas pada kata yang berwarna lebih terang. Infografis ini dilengkapi dengan background music, sound effect dan narasi. Background music berasal dari alat musik ukulele yang memiliki suasana berani dan memberikan kesan tidak takut melawan school bullying. Pada scene dampak bullying digunakan background music instrumental yang memiliki kesan kesedihan.

Objek dan background yang berbasis dua dimensi digambar langsung menggunakan pen tool. Setiap objek dipisahkan masing-masing di layer yang berbeda. Pada proses editing digunakan teknik motion graphic dengan effect animasi yang sederhana berupa position, scale dan rotation. Hasil akhir perancangan infografis ini berupa video dengan format mp4.

Pada proses pencarian data untuk perancangan infografis ini ditemukan kendala. Seperti memperoleh data dari pihak KPAI dan beberapa yayasan sosial. Oleh karena itu referensi yang dicari hanya lewat internet dan studi pustaka. Pada proses pengerjaannya relatif lama karena harus meringkas fakta, jenis-jenis dan dampak-dampak school bullying. Untuk selanjutnya perolehan data dapat dilakukan dengan mendatangi secara langsung kantor KPAI atau yayasan sosial lainnya untuk memperoleh data yang terbaru dan lebih lengkap.

Animasi infografis ini masih sederhana dan terbatas. Diperlukan untuk menambah keahlian dalam desain grafis dan keterampilan dalam menerapkan effect. Selain itu disarankan untuk memperbanyak referensi tentang animasi infografis. Karena seiring berjalannya waktu teknik animasi semakin berkembang pesat sehingga diperlukan penyesuaian dengan teknik yang terupdate.

Proses perancangan infografis dengan tema school bullying di tingkat SMA dan sederajat ini tentu saja belum sempurna. Perancangan infografis ini belum lengkap memberikan latar belakang school bullying dan dampak-dampak yang dialami oleh pelaku, korban dan yang melihat school bullying. Dikarenakan terbatasnya ruang infografis, dampak dampak school bullying yang ditampilkan hanya beberapa yang dianggap penting. Oleh karena itu infografis ini dapat dikembangkan lagi dengan lebih baik.

Kedepannya diharapkan infografis ini bisa dikembangkan menjadi infografis interaktif. Infografis interaktif dapat menyampaikan pesan lebih banyak dan lengkap. Penonton dapat berinteraksi dengan infografis karena disediakan pilihan untuk melihat 
informasi yang diinginkan. Infogratis interaktif akan memikat minat siswa SMA yang memiliki rasa penasaran dan keingintahuan yang tinggi.

\section{DAFTAR PUSTAKA}

Halimah, Andi. Persepsi pada Bystander terhadap Intensitas Bullying pada Siswa SMP. http://jurnal.ugm.ac.id/jpsi/article/download/7168/ 5612. 2015.

Wiyani, Novan Ardy. Save Our Children From School Bullying. Yogjakarta. Ar-Ruzz Media. 2012.

Crooks, R. Our Sexuality. California. Thomson Wadsworth. 2002. 